\title{
Pregnancy and the biliary system
}

\author{
HELGA WITT, MD, FRCPC, J JOSEPH CONNON, MD, FRCP(LOND), FRCPC
}

\begin{abstract}
Alterations in the synthesis and secretion of bile salts and cholesterol and in gallbladder function occur during pregnancy. These changes are related to the effects of estrogen and progesterone. Biliary cholesterol saturation and the cholic acid/chenodeoxycholic acid ratio increase. Progesterone also diminishes gallbladder contractility and emptying. Gallstones occur in 2.5 to $11 \%$ of pregnant women and are associated with cholecystitis in 0.008 to $0.1 \%$ of pregnant women. Operative treatment should be deferred if possible until after delivery; failing that, surgery is best done in the second trimester. Endoscopic papillotomy may prove to be the best therapy for choledocholithiasis. Can J Gastroenterol 1990;4(5):209-214
\end{abstract}

Key Words: Biliary tract, Gallstones, Pathophysiology, Pregnancy, Treatment

\section{La grossesse et le système biliaire}

RESUME: La synthèse et la sécrétion des sels biliaires et du cholestérol ainsi que la fonction de la vésicule biliaire sont modifiées pendant la grossesse. Ces changements sont reliés à l'action de l'oestrogène et de la progestérone. La saturation de la bile native en cholestérol et le rapport acide cholique/acide chénodésoxycholique augmentent. La progestérone réduit également la contractilité et l'évacuation de la vésicule. Les calculs surviennent chez 2,5 à $11 \%$ des femmes enceintes et sont associés à la cholécystite chez $0,008 \%$ à $0,1 \%$ d'entre elles. Le traitement opératoire devrait si possible être retardé après l'accouchement ou devrait alors s'effectuer de préférence au cours du second trimestre. La papillotomie endoscopique est probablement la thérapie la plus appropriée à la cholédocholithiase.

D

URING PREGNANCY, BILE FORMA. tion and gallbladder function undergo specific changes which predispose to the development of cholelithiasis. In most patients, gallstones are asymptomatic, but in some they cause biliary colic, acute cholecystitis and pancreatitis. During pregnancy, cholecystectomy is second only to appendectomy as a nonobstetric cause of laparotomy (1).

Other rarer lesions of the biliary tree reported during pregnancy include: choledochal cysts, biliary tract carcinoma and rupture of the cystic duct. In general, these lesions are not related to pregnancy per se, and their frequency is similar to that in the nonpregnant population; at best there is a weak association.

This review will examine disorders of the biliary tree in pregnancy, with emphasis on the pathogenesis and management of gallstone disease.

\section{NORMAL PHYSIOLOGY}

Prior to discussion of the pathophysiology of biliary tract disease in pregnancy, a brief review of the normal physiology is appropriate.

The chief constituents of bile are bile salts, cholesterol, phospholipids, bilirubin, electrolytes and water. Bile salts are conjugated bile acids synthesized in the liver from cholesterol. Their main function is to emulsify dietary fat and thus aid in the digestion and absorption of lipids. Excreted bile acids consist of recirculated bile acids, the major constituent, and newly synthesized bile acids (2).

The rate of synthesis of primary bile acids (cholic and chenodeoxycholic acid) from cholesterol in the liver is regulated by the activity of $7-\alpha$ hydroxylase. The activity of this enzyme is under negative feedback control, dependent on the quantity of bile salts returning to the liver via the enterohepatic circulation (3). 
The primary bile acids are conjugated with glycine and taurine, and then secreted into bile canaliculi. When they are present above a critical concentration, aggregation occurs, leading to micelle formation. Micelles have a hydrophobic centre and a hydrophilic exterior. This property allows water-insoluble compounds to be maintained in solution (4).

Cholesterol and lecithin are waterinsoluble compounds. The incorporation of lecithin, a phospholipid, into the micelle results in increased cholesterol-carrying capacity. The solubilization of cholesterol by these 'mixed' micelles is an important factor in the prevention of gallstone formation. Solubility limits of cholesterol relative to bile salt and lecithin concentrations have been well defined $(5,6)$. Outside these solubility limits bile is supersaturated with cholesterol. The term 'lithogenic bile' refers to its predisposition to gallstone formation.

Differences in 'coupling ratios' (ie, the amount of cholesterol carried per molecule of bile salt) exist between the two primary bile acids. The capacity of cholate to couple with cholesterol is greater than that of chenodeoxycholate. This accounts in part for the litholytic properties of chenodeoxycholate compared to the lithogenic properties of cholate (7). In addition to the solubility of cholesterol, other factors which play a role in stone formation include nucleating (8) and antinucleating factors (9). These enhance or discourage stone formation, respectively, but are of lesser importance compared to the solubility limits of cholesterol. The role of phospholipid vesicles in transporting biliary cholesterol and in the etiology of gallstones is still being explored.

Bile is stored in the gallbladder until the gallbladder contracts and empties its contents into the duodenum. About $90 \%$ of bile salts are actively absorbed in the distal ileum by diffusion (10). These bile acids then return to the liver via the portal circulation to complete the enterohepatic circulatory cycle. Bile salts reaching the colon are deconjugated by bacterial 7- $\alpha$-dehydroxylase to secondary bile salts (deoxycholic and lithocholic acid) and are excreted in the stool. Thus 90 to $95 \%$ of the bile salt load is conserved and recycled five to seven times per day (11).

Any mechanism whereby bile cholesterol concentration is increased or bile acid concentration decreased favours the formation of cholesterol cholelithiasis, the principal disease of the biliary tract in pregnancy. Pathogenetic factors specific to pregnancy will be discussed in further detail in the pathophysiology section.

\section{EPIDEMIOLOGY OF GALLSTONE DISEASE IN PREGNANCY}

There is substantial worldwide variation in the incidence of gallstones. In the United States, post mortem studies indicate that about $15 \%$ of the adult population has gallstones (12). Clearly, such studies are potentially biased by the age of the autopsy population. Eighty-five to $95 \%$ of these gallstones are primarily composed of cholesterol, whereas in southeast Asia bilirubin stones are more common (13). Recent Scandinavian studies have reported a significant decline in gallstone incidence which has been attributed to both decreased use of contraceptives and reduced contraceptive hormonal content (14-16).

The Framingham study (17) reviewed the rate of definite gallbladder disease (defined by autopsy or surgery) and found an increasing 10 year incidence rate for women as follows: age groups 30 to 39,40 to 49 and 50 to 62 had respective incidence rates of 30,66 and 89 per 100,000. These figures show an increase in gallstone disease with increasing age. In support of this, age has also been shown a positive correlation with rate of cholesterol secretion and a negative correlation with bile acid synthesis, both of which predispose to lithogenic bile (18).

Females are twice as likely to develop cholelithiasis as men (17). This difference becomes apparent at menarche and continues through the childbearing years (19). It should be noted, however, that with increasing age comes increasing development of gallstones in both men and women $(17,20)$.

Obesity is positively correlated with cholelithiasis, possibly because of the increased rate of cholesterol secretion in association with an unchanged bile salt secretory rate $(21,22)$.

Although the influence of pregnancy on gallstone incidence has been recognized for many years, the relationship is not quite as clearcut as was formerly thought. The Framingham study (17) showed that parity increased the risk of gallstone formation after four or more pregnancies. More recent studies have confirmed the association with pregnancy but suggest that the increased risk is confined to younger preg. nant women. Scragg (23) found that as the age of first pregnancy increased, the risk of gallstone fell. Similarly, the increased incidence of gallstones in contraceptive users is confined to women less than 29 years of age. These findings imply that pregnancy and female sex hormones unmask a subpopulation of younger women who are particularly susceptible to cholelithiasis.

In summary, the major risk factors for cholesterol gallstones are female gender, pregnancy, obesity, age and racial origin.

\section{PATHOGENESIS OF GALLSTONE FORMATION IN PREGNANCY}

Changes in both bile chemistry and gallbladder motility have been offered as an explanation for the epidemiological association of pregnancy and oral contraceptives with increased gallstone formation.

Cholesterol saturation of bile and rate of secretion of cholesterol are in. creased by both pregnancy and female sex steroids $(24,25)$. In addition, preg. nancy and sex steroids lead to an increased ratio of cholic acid to chenodeoxycholic acid in bile. The net result is increased bile lithogenicity.

Kern (26) found that administration of oral contraceptive medications led to increased secretion of biliary cholesterol, which directly paralleled cholesterol synthesis and hepatic up. take of chylomicron remnants. In a companion publication (27), the same workers reported a direct relationship between both bile acid and cholesterol synthesis in response to contraceptive 
steroids. In this setting, estrogen and progesterone caused a preferential increase in cholic acid relative to chenodeoxycholic acid, thus enhancing the lithogenic tendency of bile. It was suggested that estrogen and progesterone have different effects, estrogen acting mainly to increase hepatic uptake of cholesterol possibly by increasing receptor activity, and progesterone causing increased hepatocyte secretion of cholesterol by inhibiting the activity of the cholesterol-esterifying enzyme acylcoenzyme A: cholesterol acyltransferase. The effect of estrogen on hepatic cholesterol uptake is supported by another study in postmenopausal women in whom estrogen administration increased biliary cholesterol without affecting intestinal absorption or hepatic synthesis (28).

The role of phospholipid vesicles or nucleating and antinucleating factors in stone formation has not been explored during pregnancy or in response to sex hormones.

A recent prospective study from Italy (29) has demonstrated the dynamic nature of gallstone formation and dissolution during pregnancy. The formation of both sludge and stones increased progressively during pregnancy with a cumulative incidence of sludge and stones immediately after delivery of 41 and $9.6 \%$, respectively. In many of these women, sludge and stones disappeared both during and following pregnancy.

The effects of estrogen on biliary cholesterol saturation are supported by a recent study on estrogen-induced gallstone formation in males. The patients were being treated for carcinoma of the prostate with estrogen, which resulted in five of 37 patients on estrogen developing gallstones, while none of the control orchidectomy patients developed stones. Biliary lipids and phospholipids also increased and chenodeoxycholic acid decreased moderately in the estrogen-treated group (30).

Pregnancy also has a deleterious effect on gallbladder contractility which begins during the second trimester (31) and results in increases in gallbladder volume during fasting - as well as in residual volume after contraction which are twice those of nonpregnant females $(31,32)$. There is also a decreased rate $(31)$ and percentage $(31,33)$ of emptying. The common bile duct size remains within normal limits (34).

Progesterone is believed responsible for these effects by inhibition of smooth muscle function. Experiments using pregnant guinea pigs show decreased gallbladder contractility in response to acetylcholine and cholecystokinin, but no change in the face of increased extracellular potassium. This result suggests that progesterone may specifically affect a step in the excitation-contraction coupling process common to both acetylcholine and cholecystokinin (35).

It is believed that the combination of gallbladder stasis and lithogenic bile allows formation of cholesterol crystals and eventual gallstones.

\section{CLINICAL ASPECTS OF CHOLELITHIASIS IN PREGNANCY}

The major areas to be discussed relate to differences in incidence, clinical features, diagnosis and management of symptomatic gallstones in pregnancy. Incidence: Although there is good evidence for the de novo formation of gallstones and sludge during pregnancy, it is not clear from the available literature whether there is also an increase in the incidence of symptomatic gallstone disease. At any rate, biliary tract problems are relatively uncommon in pregnant women, falling well behind appendicitis as a cause of nonobstetric laparotomy. The incidence of gallstones in pregnancy has been quoted as ranging from 2.5 to $11.3 \%(37-39)$, but any consideration of these figures must take into account the tendency towards increased stone formation throughout pregnancy, as well as the dynamic nature of stone formation and dissolution. The prevalence of acute cholecystit is in pregnancy ranges from 0.008 to $0.1 \%$ $(1,40)$.

Clinical features: The manifestations of biliary colic are similar in pregnant and nonpregnant women. Pain, which lasts up to several hours, is situated in the epigastrium or right hypo- chondrium (41-43). There is no specific relationship to ingestion of fatty foods, and in the nonpregnant patient, biliary colic is more common during the night versus day time. Unlike peptic ulcer pain, its occurrence is unpredictable, and episodic upper abdominal pain occurring daily is unlikely to be due to biliary colic.

Acute cholecystitis may occur at any time during pregnancy. It causes more severe pain of longer duration than biliary colic and is associated with tenderness and guarding in the right hypochondrium. Varying degrees of fever, vomiting, tachycardia and hypotension occur, depending on the severity of gallbladder sepsis.

The course of acute cholecystitis may be complicated by jaundice due either to the spread of inflammatory edema to the common bile duct, or to choledocholithiasis (44). The latter problem may also give rise to pancreatitis or cholangitis $(45,46)$. Acute cholecystitis must be distinguished from appendicitis, pancreatitis, perforated peptic ulcer, pneumonia, acute fatty liver of pregnancy and preeclampsia, all of which can cause similar findings.

\section{INVESTIGATIONS}

Biochemistry: Uncomplicated biliary colic causes no changes in liver function tests or white cell count. Acute cholecystitis may be accompanied by a varying degree of leukocytosis and changes in liver function caused either by adjacent hepatic inflammation, common duct edema or choledocholithiasis. Accordingly, depending on the relative contributions of these changes, either the aminotransferases or alkaline phosphatase may be increased. Acute cholecystitis may also be accompanied by an up to twofold elevations of serum amylase (44). Greater rises in amylase raise the possibility of either acute pancreatitis or choledocholithiasis.

Pregnancy is normally associated with raised levels of alkaline phosphatase of placental origin which may be a source of confusion. Measurement of gamma-glutamyl transferase can help confirm the hepatic origin of alkaline 
phosphatase. Other hepatic complications of pregnancy such as acute fatty liver or pre-eclampsia will also affect liver function tests.

Ultrasound: The advent of ultrasonic scanning has provided a safe, simple, rapid and accurate method of evaluating patients with possible gallbladder disease, making the need for oral and intravenous cholangiography virtually obsolete. Ultrasound has become increasingly accurate with time, and 95 to $99 \%$ accuracy in diagnosing cholelithiasis has been reported (47). The ultrasonic diagnosis of acute cholecystitis has a sensitivity of $94 \%$, a specificity of $85 \%$ and an overall accuracy of $88 \%$ (48). Aside from visualization of gallstones themselves, pericholecystic fluid, distension and thickening of the gallbladder wall, and ultrasound transducer-induced pain over the gallbladder are suggestive of cholecystitis (49). The demonstration of dilated bile ducts on ultrasound examination is most likely due to choledocholithiasis and should be confirmed by endoscopic retrograde cholangiopancreatography, which can be followed by endoscopic papillotomy.

Nonvisưlatization of the gallbladder on radioisotope scanning may confirm the presence of cholecystitis, but because of radiation risk to the fetus, albeit small, scanning should only be performed if the diagnosis remains unclear and the patient is deteriorating.

\section{MANAGEMENT AND TREATMENT}

Asymptomatic stones in the gallbladder of a nonpregnant individual should be left alone (1). Pregnant patients who develop acute cholecystitis should receive conservative management initially, consisting of nasogastric suction, intravenous fluids, analgesics and antibiotics (if sepsis is suspected) $(1,42,43,50)$. Resolution rates of 77 (51) to $84 \%$ (52) can be expected with medical treatment.

The timing of elective cholecystectomy following an episode of acute cholecystitis in pregnancy is controversial. Some surgeons advocate cholecystectomy during the second trimester, whereas others feel that the likelihood of a second attack is sufficiently small, and its outcome sufficiently benign to warrant postponing elective operation until after delivery. The greatest hazard of waiting relates to unsuspected choledocholithiasis, but the increasing availability of endoscopic papillotomy diminishes this risk. In areas where ready access to skilled endoscopy is limited, one may argue for a more aggressive approach to cholecystectomy during pregnancy, especially during the second trimester, if liver function tests are abnormal or bile ducts dilated.

If surgical intervention is unavoidable, then the second trimester is considered an optimal period, since the highest risk period for spontaneous abortion has passed and the uterus has not yet obscured the surgical field $(1,43,52,53)$.

Maternal morbidity and mortality do not differ from that of the nonpregnant population $(39,41)$. Fetal mortality is approximately $5 \%(39,53)$ but can be as high as $15 \%$ if surgery takes place in the first trimester $(54,55)$.

In the case of patients with choledocholithiasis during pregnancy, endoscopic papillotomy will likely become the treatment of choice (56). Complications of this procedure include bleeding, pancreatitis, cholangitis and duodenal perforation. The complication rate in skilled hands is less than $5 \%$, and appropriate shielding can diminish radiation exposure of the fetus. In view of the young age of these patients and the possibility of further gallbladder - as opposed to bile duct complications, elective cholecystectomy should be done after delivery.

Gallstone pancreatitis has been associated with a high fetal mortality of $60 \%$ (57), but a more recent study did not support these figures and proposed that the poor fetal outcome previously reported was a direct result of laparotomy done early in pregnancy (46).

\section{OTHER LESIONS}

There are a number of reports of choledochal cysts becoming symptomatic during pregnancy $(58,59)$. Such cysts usually present at an early age and are more common in females (4:1 ratio) and Orientals. Of the four types of cysts, type 1 is encountered most frequently. This type is defined as spherical dilatation of the common bile duct with distal narrowing (58). Typical features include pain, jaundice and right upper quadrant mass.

It has been suggested that the compressive effect of the enlarging uterus impairs emptying of the choledochal cyst, leading to the development or worsening of symptoms related to the cyst (59). The coincidental finding of a cholangiocarcinoma complicating a choledochal cyst in pregnancy has been reported (60).

Treatment of asymptomatic cysts can be deferred until after delivery, at which time the appropriate treatment consists of resection to avoid development of cholangiocarcinoma. The onset of complications such as obstructive jaundice or cholangitis during pregnancy should be treated by percutaneous transhepatic drainage. Two cases of rupture $(61,62)$ and one of 'im. pending rupture' (63) of choledochal cysts have been described in pregnancy and are clear indications for surgery.

Spontaneous rupture of the common bile duct in pregnancy has also been described (64). The association with pregnancy is likely coincidental.

ACKNOWLEDGEMENTS: The authors thank Mrs G Cole for her typing assistance in the preparation of this manuscript.

\section{REFERENCES}

1. Woodhouse DR, Haylen B. Gallbladder disease complicating pregnancy. Aust N Z Obstet Gynecol 1985;25:233.

2. Sherlock S. Diseases of the Liver and Biliary System, 8th edn. Oxford: Blackwell Scientific Publications, 1985:25.

3. Mosbach EH. Hepatic synthesis of bile acids. Arch Intern Med 1972;130:478 87.

4. Sherlock S. Diseases of the Liver and Biliary System, 8th edn. Oxford:Black. well Scientific Publications, 1989:656.

5. Admirand WH, Small DM. The physicochemical basis of cholesterol gallstone formation in man. J Clin Invest 1968;47:1043-52

6. Carey MC, Small DM. The physical chemistry of cholesterol solubility in bile. J Clin Invest 1978;61:998-1026.

7. Smallwood RA, Hoffman NE. Bile acid structure and biliary secretion of 
cholesterol and phospholipid in the cat. Gastroenterology 1976;71:1063-6. Burnstein MJ, Ilson RG, Petronica $\mathrm{CN}$, Strasberg S. Evidence for a potent nucleating factor in the gallbladder bile of patients with cholesterol gallstones. Gastroenterology $1983 ; 85: 801-7$

Kibe A, Holzbach RT, LaRusso NF, et al. Inhibition of cholesterol crystal formation by apolipoproteins in supersaturated model bile. Science 1984;225:514-6.

10. Lack L, Weiner IM. The role of the intestine during the enterohepatic circulation of bile salts. Gastroenterology 1967:52:282-7.

11. Small DM, Dowling RH, Redinger RN. The enterohepatic circulation of bile salts. Arch Intern Med 1972;130:552-73.

12. Glenn F. Biliary tract disease. Surg Gynecol Obstet 1981;153:401.

13. Small DM. The formation and treatment of gallstones. In: Schiff L, Schiff ER, eds. Disease of the Liver, 5 th edn. Philadelphia: Lippincott, 1982:151-66.

14. Evron S, Frankel M, Diamant Y. Biliary disease in young women and its association with pregnancy or oral contraceptives. Int Surg 1982;67:448-50.

15. Jarnfelt-Samside A, Eriksson B, Leissner KH, Samside G. Gallbladder disease related to use of oral contraceptives and nausea in pregnancy. South Med J 1985;78:1040-3.

16. Janzon L, Aspelin P, Eriksson S, Hildell J, Trill E, Ostberg H. Ultrasonographic screening for gallstone disease in middle-aged women. Scand J Gastroenterol 1985;20:706-10

17. Friedman GD, Kannel WB, Dawber TR. The epidemiology of gallbladder disease: Observations in the Framingham study. J Chron Dis 1966;19:273-92

18. Einarsson K, Nilsell K, Leij DB, Angelin B. Influence of age on secretion of cholesterol and synthesis of bile acids by the liver. N Engl J Med 1985;313:277-82.

19. Nilsson S. Gallbladder disease and sex hormones. A statistical study. Acta Chir Scand 1966;132:275-9.

20. Zahor Z, Sternb NH, Kaga NA, et al. Frequency of cholelithiasis in Prague and Malmo. An autopsy study. Scand J Gastroenterol 1974;9:3-7.

21. Morrissey K, Panveliwalla D, McSherry C, Dietrick J, Niemann W, Gupta G. Effects of contraceptive steroids and pregnancy on bile composition and kinetics in the baboon. J Surg Res 1977;22:598-604.

22. Honore LH. Cholesterol cholelithiasis in adolescent females. Arch Surg 1980;115:62-4.
23. Scragg RKR, McMichael AJ, Seamark RF. Oral contraceptives, pregnancy and endogenous estrogen in gallstone disease. A case-control study. $\mathrm{Br}$ Med J 1984:288:1795-9.

24. Kern F Jr, Everson GT, DeMark B, et al. Biliary lipids, bile acids and gallbladder function in the human female - Effects of pregnancy and the ovulatory cycle. J Clin Invest 1981;68:1229-42.

25. Bennion LJ, Mott DM, Howard BV. Oral contraceptives raise the cholesterol saturation of bile by increasing biliary cholesterol secretion. Metabolism 1980;29:18-22

26. Kern F Jr, Everson GT. Contraceptive steroids increase cholesterol bile: Mechanisms of action. J Lipid Res 1987;28:828-39.

27. Everson GT, Fennessey P, Kern F Jr. Contraceptive steroids alter the steady state kinetics of bile acids. J Lipid Res 1988;29:68-76.

28. Everson GT, Kern F Jr. Mechanisms of gallstone formation in postmenopausal women taking conjugated estrogen (Premarin). Gastroenterology 1988;94:A538.

29. Maringhini A, Ciambra M, Baccelliere P, Raimondo M, Pagliaro L. Sludge, stones and pregnancy. Gastroenterology 1988;95:1160-1

30. Henriksson P, Einarsson K, Eriksson A, et al. Estrogen induced gallstone formation in males. J Clin Invest 1989;84:811-6.

31. Braverman DZ, Johnson ML, Kern F Jr. Effects of pregnancy and contraceptive steroids on gallbladder function. N Engl J Med 1980;302:362-4.

32. Kirkinen P, Ylostalo P, Heikkinen J, Maentausta O. Gallbladder function and maternal bile acids in intrahepatic cholestasis of pregnancy. Eur J Obstet Gynecol Reprod Biol 1984:18:29-34.

33. Ylostalo P, Kirkinen P, Heikkinen J, Maentausa O, Jarvinen PA. Gallbladder volume and serum bile acids in cholestasis of pregnancy. $\mathrm{Br}$ ] Obstet Gynaecol 1982;89:59-61

34. Mintz MC, Grumbach K, Arger PH, Coleman BG. Sonographic evaluation of bile duct size during pregnancy. Am J Radiol 1985; 1.45:575-8.

35. Ryan JP. Effect of pregnancy on gallbladder contractility in the guinea pig. Gastroenterology 1984;87:674-8.

36. Leissner KH, Wedel H, Schersten T. Comparison between the use of oral contraceptives and the incidence of surgically confirmed gallstones disease. Scand J Gastroenterol 1977;12:893-6.

37. Carten KJ, Pulliam RP. Cholelithiasis in pregnancy. West Virginia Med J 1985:81:75-6.

38. Williamson SL, Williamson MR.
Cholecystosonography in pregnancy.

J Ultrasound Med 1984;3:329-31.

39. Stauffer RA, Adams A, Wygal J, Lavery JP. Gallbladder disease in pregnancy. Am J Obstet Gynecol 1982;144:661-4.

40. Friley MD, Douglas G. Acute cholecystitis in pregnancy and the pueruerium. Am Surg 1972;38:314-7.

41. Hill LM, Johnson CE, Lee RA. Cholecystectomy in pregnancy. Obstet Gynecol 1975;46:291-3.

42. DeVore GR. Acute abdominal pain in the pregnant patient due to pancreatitis, acute appendicitis, cholecystitis or peptic ulcer disease. Clin Perinatol 1980;7:349-69.

43. Simon JA. Biliary tract disease and related surgical disorders during pregnancy. Clin Obstet Gynecol 1983;26:810-21.

44. Block P, Kelly TR. Management of gallstone pancreatitis during pregnancy and the postpartum period. Surg Gynecol Obstet 1989;168:426-8.

45. Haemmerli UP. Jaundice during pregnancy with special reference to recurrent jaundice during pregnancy and its differential diagnosis. Acta Med Scand 1966;444(Suppl):1.

46. McKay AJ, O'Neill J, Imrie CW. Pancreatitis, pregnancy and gallstones. Br J Obstet Gynaecol 1980;87:47.

47. Laing FC. Diagnostic evaluation of patients with suspected acute cholecystitis. Radiol Clin North Am 1983;21:477.

48. Laing FC, Federle MD, Brooke Jeffery R, Brown TW. Ultrasonic evaluation of patients with acute right upper quadrant pain. Radiology $1981 ; 140: 449-55$.

49. Zeman RK, Jaffe MH, Grant EG, et al. Imaging of the liver, biliary tract and pancreas. Med Clin North Am 1984;68:1535-63.

50. Holman KG, Montgomery PJ, Devabhaktunt D. Gallbladder disease in pregnancy. Am Fam Phys $1985 ; 32: 147$.

51. Hiat JR, Hiat JCG, Williams RA, Klein S. Biliary disease in pregnancy: Strategy for surgical management. Am J Surg 1986;151:263-5.

52. Landers D, Carmona R, Crombleholme W, Lim R. Acute cholecystitis in pregnancy. Obstet Gynecol 1987;69:131-3.

53. Kammerer WS. Non-obstetric surgery during pregnancy. Med Clin North Am 1979;6:1157-64.

54. Macbeth RA. Acute surgical disease of the abdomen complicating pregnancy. Can J Surg 1961:4:419-29.

55. Greene J, Rogers A, Rubin L. Fetal loss after cholecystectomy during pregnancy. Can Med Assoc J $1963 ; 88: 576-7$ 
56. Baillie J, Cairns SR, Cotton PB. Endoscopic management of choledocholithiasis during pregnancy. Gastroenterology 1988;94:18. (Abst)

57. Printen KJ, Ott RA. Cholecystectomy during pregnancy. Am Surg 1978;44:432-4.

58. Taylor TV, Brigg JK, Russell JGB, Torrance B. Choledochal cyst of pregnancy. J R Coll Surg Edin 1977-8;22-3:424-7.
59. Angel IL, Knuppel RA, Trabin J. Choledochal cyst complicating a twin gestation. South Med J 1985;78:463-6.

60. Devoe LD, Mossa AR, Levin B. Pregnancy complicated by extrahepatic biliary tract carcinoma. A case report. J Reprod Med 1983;28:153-5.

61. Saunders P, Jackson BT. Rupture of choledochus cyst in pregnancy. Br Med J 1969;3:573-4.

62. Friend WD. Rupture of choledochal cyst during confinement. Br ] Surg 1958:46:155-7.

63. Kitahama A, Harkness SO, Moynihan PO, Webb WR. A large choledochal cyst with impending rupture. $\mathrm{Br}]$ Surg 1984;71:156.

64. Lemay M, Granger L, Verschelden G, Giazrd Y, Duguay L, Lavoie P. Spontaneous rupture of the common bile duct during pregnancy. Can Med Assoc J 1980;122:14-5. 


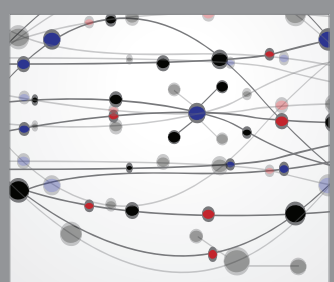

The Scientific World Journal
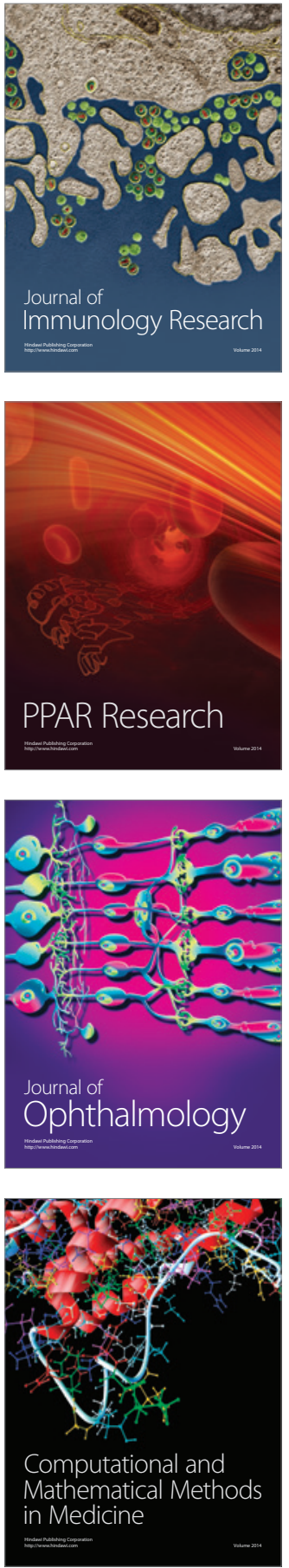

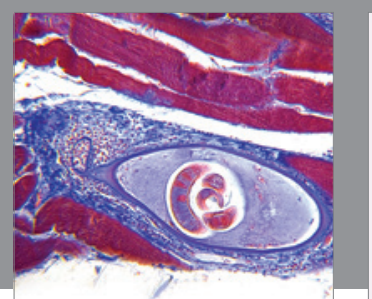

Gastroenterology Research and Practice

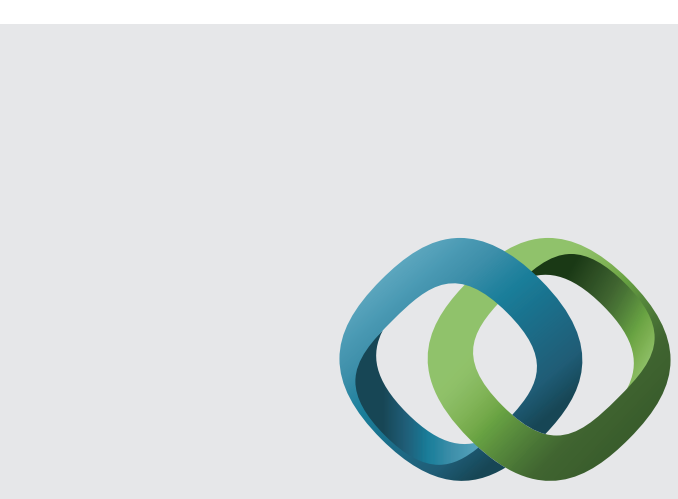

\section{Hindawi}

Submit your manuscripts at

http://www.hindawi.com
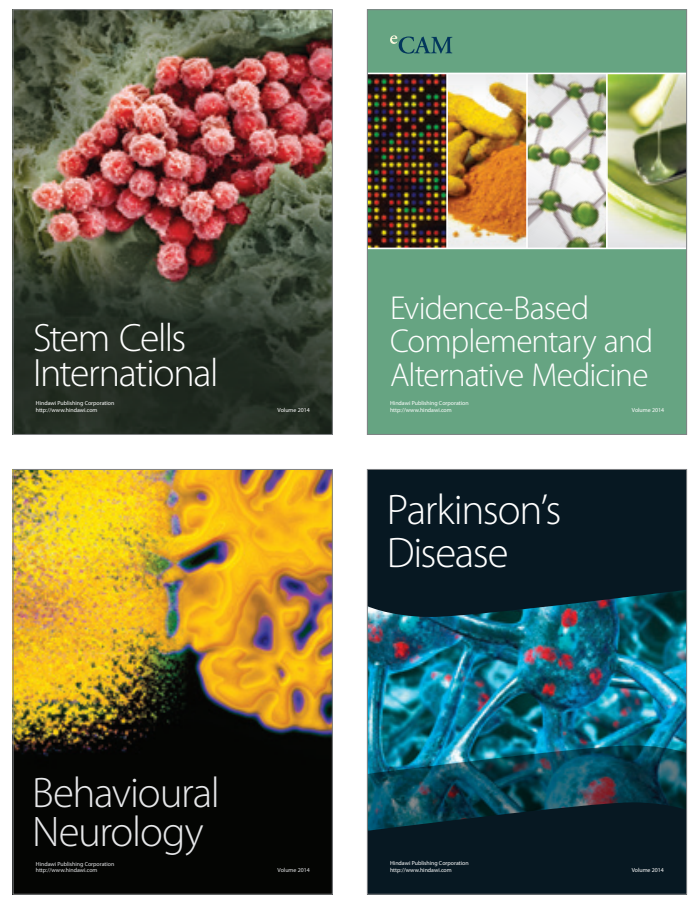
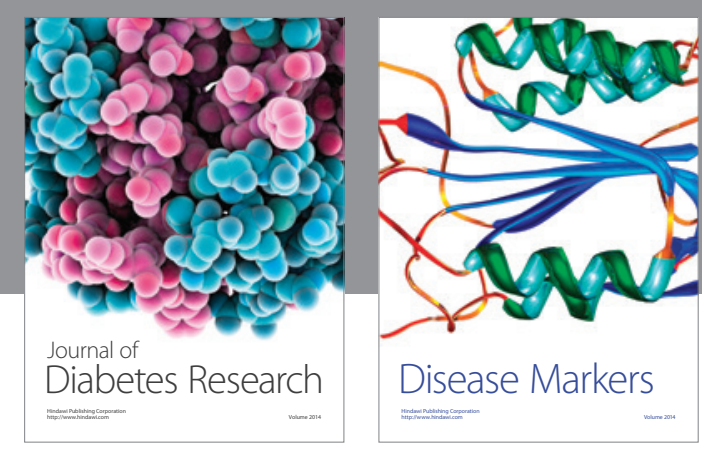

Disease Markers
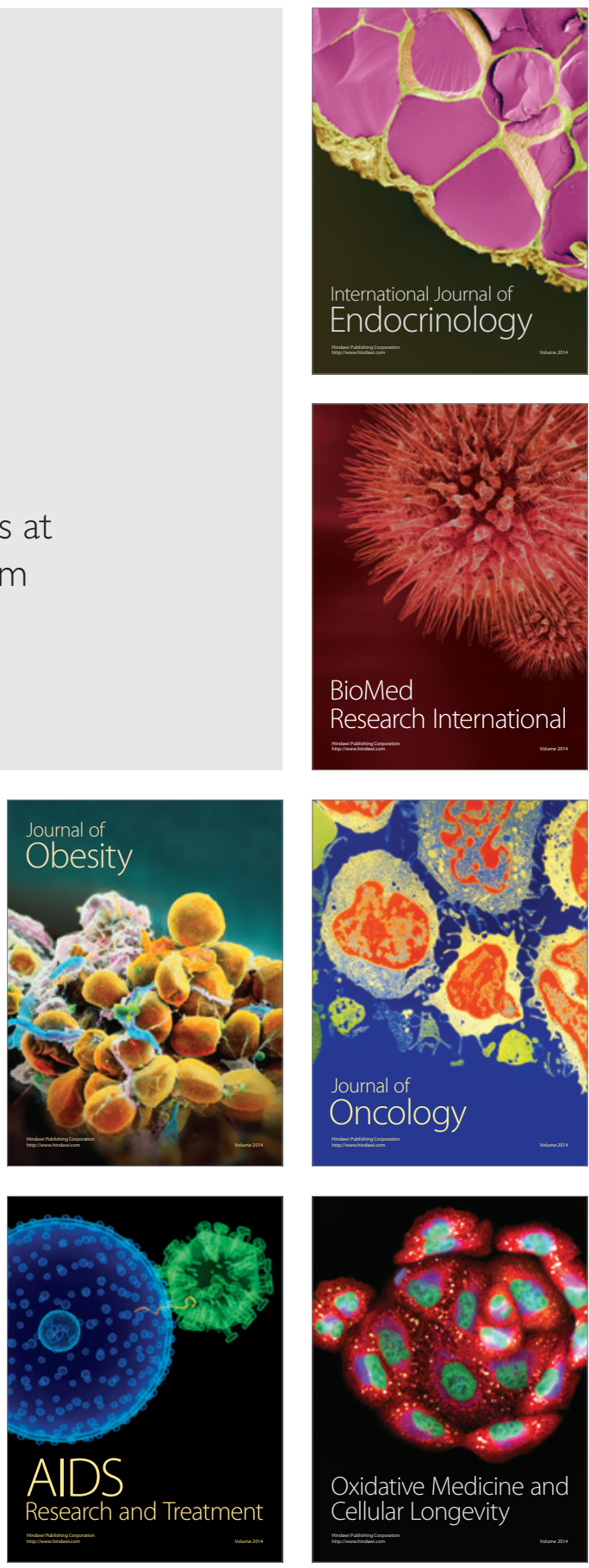